FEDERAL RESERVE BANK OF SAN FRANCISCO

WORKING PAPER SERIES

\title{
Inequality and Mortality: New Evidence from U.S. County Panel Data
}

\author{
Mary C. Daly, \\ Federal Reserve Bank of San Francisco \\ Daniel J. Wilson, \\ Federal Reserve Bank of San Francisco
}

May 2013

Working Paper 2013-13

http://www.frbsf.org/publications/economics/papers/2013/wp2013-13.pdf

The views in this paper are solely the responsibility of the authors and should not be interpreted as reflecting the views of the Federal Reserve Bank of San Francisco or the Board of Governors of the Federal Reserve System. 


\title{
Inequality and Mortality: New Evidence from U.S. County Panel Data
}

\author{
Mary C. Daly and Daniel J. Wilson \\ Federal Reserve Bank of San Francisco
}

First Draft: April 2011

Current Draft: May 2013

Keywords: Inequality, mortality, relative income, health.

JEL Codes: I31, D6, H0, J0

Corresponding author’s email: mary.daly@sf.frb.org

Research results and conclusions expressed are those of the authors only and do not necessarily indicate concurrence by the Federal Reserve Bank of San Francisco, or the Federal Reserve System. We thank the Census Bureau, and particularly Kirby Posey, for providing the data on county-level income inequality. We also thank Leila Bengali for excellent research assistance. Lastly, we are grateful to Marianne Bitler, Richard Burkhauser, Louise Slaughter, and seminar participants at the Federal Reserve Bank of New York for helpful comments. 


\title{
Inequality and Mortality: New Evidence from U.S. County Panel Data
}

\begin{abstract}
:
A large body of past research, looking across countries, states, and metropolitan areas, has found positive and statistically significant associations between income inequality and mortality. By contrast, in recent years more robust statistical methods using larger and richer data sources have generally pointed to little or no relationship between inequality and mortality. This paper aims both to document how methodological shortcomings tend to positively bias this statistical association and to advance this literature by estimating the inequality-mortality relationship. We use a comprehensive and rich new data set that combines U.S. county-level data for 1990 and 2000 on age-race-gender-specific mortality rates, a rich set of observable covariates, and previously unused Census data on local income inequality (Gini index and three income percentile ratios). Using panel data estimation techniques, we find evidence of a statistically significant negative relationship between mortality and inequality. This finding that increased inequality is associated with declines in mortality at the county level suggests a change in course for the literature. In particular, the emphasis to date on the potential psychosocial and resource allocation costs associated with higher inequality is likely missing important offsetting positives that may dominate.
\end{abstract}

Keywords: Inequality, mortality, relative income, health.

JEL Codes: I31, D6, H0, J0 


\section{Introduction}

Rapid growth in income inequality in the United States and other industrialized nations over the past three decades has raised numerous concerns among policymakers. One of the more worrisome is the possibility that income inequality might be causally related to mortality. Prima facie evidence of such a link in the United States comes from the facts that the country's income distribution is among the most unequal in the industrialized world and its life expectancy lags behind that of most developed nations. The potential for such a relationship has generated considerable attention in the media, medical journals, and grant-making institutions. It is one of the most studied issues in public health and economics.

Empirical research examining the causal linkages between inequality and mortality has produced mixed and often contradictory results. Early research across a variety of disciplines, looking across countries, states, and metropolitan statistical areas (MSAs), generally has found positive and statistically significant associations between inequality and mortality. ${ }^{1}$ More recent efforts using richer data sources that allow more rigorous statistical methods have found little or no association between inequality and mortality. ${ }^{2}$ Considering over 100 studies of the topic, Clarkwest and Jencks (2003) conclude that (1) there is no consensus among scholars, and (2) the evidence on either side is too weak to decide between competing claims of a small harmful effect and no effect at all. Similarly, Lynch,

\footnotetext{
${ }^{1}$ For example, Wilkinson 1992; Ben-Shlomo, White, and Marmot 1996; Kaplan et al. 1996; Kennedy, et al. 1996a; Kawachi and Kennedy 1997; Kawachi et al. 1997; Lynch et al. 1998; Lobmayer and Wilkinson 2000; Ross et al. 2000; Lochner et al. 2001; Lynch et al. 2001; McLaughlin and Stokes 2002; Sanmartin et al. 2003; Shi et al. 2003.

${ }^{2}$ For example, see Judge, Mulligan, and Benzeval 1998; Deaton and Lubotsky 2003; Deaton and Paxson 2001; Clarkwest and Jencks 2003; and Gerdtham and Johannesson 2004. 
et al. (2004) consider nearly 100 studies on the relationship between income inequality and health and conclude that "there seems to be little support for the idea that income inequality is a major, generalizable determinant of population health differences within or between rich countries.” Most recently, Kondo et al. (2009) performed a meta-analysis of the estimated effect of inequality on mortality based on 39 distinct estimates from 28 separate cohort and cross-sectional studies. About half of the estimates were positive and statistically significant at the 95\% confidence level; the remaining estimates were not significantly different from zero. Only three estimates were negative, and none of these was statistically significant. In addition, they report that the positive effect tends to be reduced or eliminated in analyses that control for unobserved local characteristics. This is particularly interesting considering our finding that controlling for unobserved local characteristics (fixed effects) is critically important for obtaining a negative inequalitymortality link.

The mixed results in this literature have left the scholarly community at an impasse. Proponents maintain that a positive causal link exists but is difficult to observe, while skeptics point to an absence of robust evidence. In part, the continued debate owes to limitations in the data and associated methods that prevent definitive testing of an effect that is free of spurious correlations with other variables.

In general, studies of income inequality and mortality fall into one of three types. The first type is cross-sectional studies across geographic areas (states, counties, or MSAs) within a country. ${ }^{3}$ These studies typically use nationally representative data and often include important local covariates in addition to inequality. However, given their cross-

\footnotetext{
${ }^{3}$ Examples include Kaplan et al. 1996; Kennedy et al. 1996; Kawachi et al. 1997; and Lynch et al. 1998.
} 
sectional nature, they cannot control for unobserved local characteristics (fixed effects). They also often lack accurate measures of inequality, relying instead on relatively crude metrics such as the ratio of the mean to the median income. The second type is individual level longitudinal studies, which typically have rich sets of individual covariates and local level inequality, but omit important local covariates and do not allow for local fixed effects. ${ }^{4}$ In addition, these studies tend to have small samples that limit the statistical power of any analysis. The third type of study is cross-country or cross-state panel studies, which control for country/state fixed effects to account for geographic differences in mortality rates that are unrelated to income inequality. ${ }^{5}$ The drawback of these studies is that they tend to rely on very limited sets of covariates. Moreover, because health may depend on local factors, the state or country level may be too large of a geographic area to capture these effects.

Studies that find significant effects of inequality on mortality frequently are subject to methodological criticisms including the failure to control for individual or regional differences in mortality risk. On the other hand, studies which find no effect generally face challenges of small sample size which reduce the researcher's ability to precisely estimate any effect. These studies most frequently conclude that inequality has no "statistically significant” effect; however, the lack of precision suggests that this conclusion reflects an absence of evidence for an effect, rather than evidence that there is no effect.

What, then, can researchers do to resolve the impasse in the literature? Clarkwest and Jencks (2003) are pessimistic on the issue. They conclude that no available data exist

\footnotetext{
${ }^{4}$ Examples include Lochner et al. 2001; Eibner and Evans 2005; Deaton and Paxson 2001; and Mellor and Milyo 2002, 2003.

${ }^{5}$ Examples include Judge, Mulligan, and Benzeval 1998; Mellor and Milyo 2002; and Leigh and Jencks 2007. 
to sufficiently address all of the empirical shortcomings of previous studies simultaneously. They say, "There is no realistic prospect of getting better data that will settle this debate any time soon. Most observers will therefore continue to base their judgments on their prior beliefs." We are more optimistic that additional work can be done. As such, we have assembled a data set that fills in many of the gaps from previous studies.

In this paper, we combine county panel data on group-specific mortality rates, a rich set of county observable covariates, and previously unused Census data on county income inequality to estimate the effects of inequality on mortality risk. We use these data to estimate the effects of income inequality on mortality risk in the United States. To ensure consistency with previous results, we begin by replicating key findings of previous analyses. Specifically, we confirm the strong positive association between inequality and mortality in simple bivariate and multivariate regressions. We then show that this correlation disappears when local covariates and/or state fixed effects are added to the regression.

After we demonstrate the consistency of our data with the prior literature, we refine our specification of the model to include controls for local, time-invariant unobservables (i.e., county fixed effects). In this specification, we show that income inequality is negatively related to mortality risk. This effect is statistically significant and it holds true for both overall inequality and for inequality in the top half and bottom half of the income distribution independently. These results suggest that a new direction in research on inequality and mortality may be warranted. 


\section{Theoretical Links between Inequality and Health}

Most explanations for an association between income inequality and mortality fall into two categories: economic and psychosocial. The economic explanations rest on the premise that, at the individual level, the relationship between mortality and income is nonlinear; that is, if inequality in the income distribution produces unequal access to services such as education, health care, and police protection, the negative effects for those at the bottom of the distribution will not be offset by positive outcomes for those at the top of the distribution. ${ }^{6}$ Moreover, the negative health outcomes of an unequal income distribution may not be limited to the portion of the population with fewer resources. Differential access to resources and services may result in less effective preventive health care (e.g., childhood vaccinations), more costly disease control (e.g., tuberculosis treatments), or higher crime rates, affecting the health and mortality risk of the entire population. $^{7}$

The psychosocial hypothesis suggests that it is one's relative income position itself that matters for their health and mortality risk. Under this hypothesis, income inequality and mortality risk are linked through the effects of emotional and psychological stress on health. ${ }^{8}$ The theory posits that levels of depression, isolation, insecurity, and anxiety, which are known correlates of mortality, are associated with relative economic position. In addition, some argue, inequality inhibits many of the social behaviors that may reduce stress and anxiety, such as participation in voluntary organizations or community groups

\footnotetext{
${ }^{6}$ This argument leads Clarkwest and Jencks (2003) to conclude that, unless income inequality has some type of protective effect that operates independently of one's own income, the impact of inequality must be to lower life expectancy or increase mortality.

${ }^{7}$ Kaplan et al. (1996) lay out the reasoning behind the economic pathways between income inequality and mortality.

${ }^{8}$ The psychosocial hypothesis is associated with the Whitehall Studies and Wilkinson (1992).
} 
and investment in ongoing education and training.

Which of these two pathways, if either, connects aggregate income inequality to individual health outcomes is an empirical question that researchers have made little progress in addressing. The bulk of the empirical research on mortality and inequality has focused less on identifying the causal pathway and more on establishing that a statistical linkage between the two exists. For the most part, this paper continues along the latter course. However, by looking separately at the effects of top-half and bottom-half inequality and at the effects of inequality on different causes of death, we also are able to shed some light on the likely pathways underlying the overall statistical linkage.

\section{Data and Methods}

The data used in this paper come from two main sources: the Compressed Mortality Files (CMF) from the National Center for Health Statistics, and the U.S. Census Bureau. The CMF data provide by-cause mortality counts and rates (per 100,000 population) by gender-age-race-county cells from 1989 through 2002. These data cover all deaths recorded in the United States (including deaths for which individual information is not publicly available). We use these data to construct all-cause and cause-specific mortality rates by gender-age-race-county cells in 1990 and 2000, measuring age in 10-year reference groups and race as white, black, and other. To minimize the frequency of zero mortalities in a given year at this disaggregated cell level (especially for certain causes), we average the mortality rate within each cell over 1989 and 1990 and treat the result as the "1990" mortality rate. Likewise, we use 1999 and 2000 averages for the 2000 values. The final data set contains roughly 330,000 cells (approximately 3,100 counties $\times 3$ races (white, 
black, other $) \times 2$ genders $\times 11$ age groups $\times 2$ years $=409,200$ possible cells, minus around 80,000 empty cells).

We combine the mortality data with data provided from the Census Bureau on county-level income inequality calculated from household-level data collected in the 1990 and 2000 decennial censuses. (Data from other decennial census years were not available.) To the best of our knowledge, these data have not been used previously in this literature. ${ }^{9}$ We use four measures of inequality from the data: the Gini coefficient and three income percentile ratios: 95/20, 95/50, and 50/20. The Gini coefficient is commonly used in the income inequality literature and is included in our county-level data. One drawback of the Gini coefficient does not allow one to decompose total inequality into dispersion in the top half and bottom half of the income distribution. We use the percentile ratios to solve this problem. As the names suggest, these ratios are ratios of the income levels at two percentiles of the income distribution. For example, the 95/20 measures overall income inequality according to the ratio of the $95^{\text {th }}$ percentile to the $20^{\text {th }}$ percentile. The $95 / 50$ ratio measures income inequality in the top half of the distribution, and the 50/20 ratio measures inequality in the bottom half.

Lastly, we compile data for a host of demographic and socioeconomic covariates. From the Census Bureau's USA Counties database, we obtained county-level data for 1990 and 2000 on the poverty rate (by race within county), the crime rate (number of serious crimes per capita), the share of the population in each educational category (less than high school, high school but no diploma, high school graduate or equivalency, some college but no degree, associate degree, bachelor degree, some graduate school but no degree, graduate

\footnotetext{
${ }^{9}$ These data are available for public use, though they are not published or provided on the Census Bureau website.
} 
or professional degree), the share of population of each race (white, black, or other), the share of population by age group (less than 20, 20 to 64, 65 and above), average family size, share of population by marital category (by male and female: never married, married, separated, divorced, widowed, other), population density, share of county population on social security disability, share of population living in institutions, latitude, and longitude. From the Bureau of Labor Statistics, we obtained the average annual unemployment rate in 1990 and 2000 in each county.

\section{Results}

We use these data to estimate the effects of inequality on mortality risk. It is useful first to consider the simple cross-sectional relationship between these two variables. Figure 1 shows a simple scatter plot of all-cause mortality rates versus income inequality for 1990 and 2000. We measure income inequality here using the 95/20 percentile ratio; the results are quite similar using the Gini coefficient. To ease visualization of the data, we group counties into 313 bins of approximately 10 counties each after ranking counties by their 95/20 ratios. For each bin, the data point shows the population-weighted mean of the 95/20 ratio on the $\mathrm{x}$ axis and the population-weighted mean of the mortality rate (deaths per 100,000 persons) on the y axis. Figure 1 shows a clear positive raw correlation between income inequality and mortality across counties in both 1990 and 2000.

We explore the relationship between inequality and mortality shown in the scatter plot more formally using Poisson and negative binomial maximum likelihood estimation. ${ }^{10}$ In all cases, we adjust standard errors for clustering of observations within a county. This

\footnotetext{
${ }^{10}$ The results presented in the tables in this section are based on the Poisson regressions. The results using negative binomial are virtually identical and, hence, are not shown. 
clustering allows for correlated observations within a county both across age-race-gender cell groups and across years (to allow, for example, for serial correlation between 1990 and 2000).

We begin by considering the county-level relationship between income inequality, measured by the $95 / 20$ percentile ratio, and the age-race-gender all-cause mortality rate. Table 1 shows the results of this analysis for a variety of model specifications. Each column heading ( 1 to 4 ) denotes a separate regression; we provide coefficients and their corresponding Z-statistics for the key variables of interest.

We base the results under column headings (1) and (2) on model specifications that are quite restrictive but similar to what has been estimated extensively in previous research. Column (1) reports results for a simple Poisson regression of age-race-gender-year mortality rates on age, race, gender, and year dummy variables and the county-level Gini coefficient. Consistent with the simple bivariate scatter plots discussed earlier, this regression yields a positive and statistically significant (below the 1\% level) relationship. Column (2) shows results of a specification that adds two key conditioning variables: (the log of) median county income and the county-race-specific poverty rate. As expected given the prior literature, the magnitude of the association between inequality and mortality falls, but the estimate remains statistically significant (below the 1\% level). The results in columns (1) and (2) confirm the oft-cited positive association between inequality and mortality risk in aggregate cross-sectional data.

Moving across the table, column (3) shows that adding a richer set of local covariates reduces the estimated inequality effect to near zero. This result is consistent with the findings from much of the recent literature using richer data sources, which report little 
evidence of a quantitatively meaningful impact of inequality on mortality. Though not shown in the table (to save space), the results are similar when state-level fixed effects are added.

The final specification in the table (column (4)) departs from previous work by controlling for time-invariant, local unobservables, i.e., county fixed effects. As the table shows, adding county fixed effects to the rich set of time-varying county controls yields a negative effect of inequality on mortality risk that is statistically significant (below the 5\% level). This result is a reversal of prior findings. To visualize the magnitude of this shift, Figure 2 plots the coefficient estimates from the model specifications in Table 1. As the figure makes clear, the interpretations move from inequality being deleterious, having a large positive effect on mortality, to considering inequality as protective, having a negative effect on mortality.

Table 2 repeats the analysis from Table 1 but uses the Gini coefficient as the measure of inequality. The results are qualitatively similar to those based on the 95/20 ratio, except that the negative coefficient in the full specification is not statistically significant (at standard levels). Nonetheless, the results show a positive and significant effect of inequality in univariate and bivariate models that becomes small or insignificant when a richer set of controls are included and moves in a negative direction as local fixed effects are included.

In our final analysis we consider whether these effects persist when inequality is disaggregated into lower-half and upper-half income inequality. The results are shown in Table 3. We find that the negative effect of inequality holds much more strongly for tophalf income inequality. The coefficient on bottom-half inequality also is negative, but it is 
not statistically significant.

In Table 4, we extend the analysis by considering the effects of inequality on mortality for specific causes of death. We estimate the same county fixed effects regressions as described earlier, with the full set of covariates, separately for each of nine major causes of death. The coefficient on overall income inequality-measured by the 95/20 ratio - is negative in all cases. It is statistically significant (at the $10 \%$ level or below) for five of the nine causes (cancer, stroke, accidents, liver failure, and homicide). The results based on the Gini coefficient are broadly similar, though for two causes (heart attack and suicide) the coefficient on inequality is positive but statistically insignificant. We find the separate effects of top- and bottom-half inequality, which are estimated simultaneously in the same regression (for each cause), also generally are negative, though not always statistically significantly so. We find top-half inequality has a negative and statistically (at the 10\% level or below) significant mortality effect for cancer, liver failure, and homicide, while bottom-half inequality has a negative and statistically significant effect for stroke, accidents, and homicide.

\section{Possible Explanations for a Negative Inequality-Mortality Relationship}

Our empirical results point to a robust negative relationship between local-area income inequality and mortality after conditioning on observed and unobserved, but timeinvariant, local-area characteristics. There are two potential explanations for this result. First, unobserved time-varying local factors may be correlated with both local-area inequality and local-area mortality in a way that negatively biases the estimated relationship. Note, however, that given the strong positive association we and others find 
when controls are limited, this explanation also requires that the negative bias from omitting unobserved time-varying local factors be more than offset by a positive bias from omitting a rich set of controls. The second possible explanation is that local-area income inequality, or something proxied by inequality, has a causal negative (protective) effect on mortality.

To formally explore this latter possibility and highlight possible ways income inequality might directly affect health, we consider a simple model of community health production. We think about community health production as an increasing function of social capital, federal and state government transfers (especially Medicare and Medicaid), local government health-care spending, local private medical spending (e.g., philanthropic giving), and county socioeconomic and demographic composition. We hypothesize that (1) social capital is a decreasing function of both top-half and bottom-half inequality, (2) government transfers received from higher levels of government (state and federal) are a decreasing function of lower incomes, (3) government medical spending is an increasing function of local tax revenue, which is an increasing function of top-half inequality (due to tax progressivity), and (4) private medical spending is an increasing function of upper incomes (i.e., the good obtained from private medical spending is a luxury good).

Taken together, these hypotheses suggest that inequality in either the top- or bottom-half has offsetting effects on health. Top-half inequality harms health by reducing social capital. However, because higher top-half inequality, holding median income constant, reflects higher upper-tail incomes (95th percentile), it has a countervailing protective effect from increases in both private and government (via taxes) medical spending. Moreover, higher local government revenue could increase other public services, 
partially offsetting the hit to social capital from inequality.

Analogously, bottom-half inequality could have a harmful effect from reducing social capital. However, increasing government transfers provide a protective effect because higher bottom-half inequality, holding median income constant, implies reduced lower-tail (20th percentile) income. For instance, eligibility for Medicaid and the State Children's Health Insurance Program is determined by family income, so a shift in a county’s income distribution that pushes more people below these programs' incomeeligibility thresholds will increase transfers from the state and federal government to that county. The poverty rate in our regressions will capture some but not all of this protective effect because the income thresholds for many government health programs exceed the poverty level and hence are closer to the $20^{\text {th }}$ percentile. According to this simple model, our regression results can then be explained as follows: An increase in top-half inequality reduces social capital but increases public and private medical spending, and the latter effect dominates. In addition, the protective effect of a higher 50/20 ratio from increased government transfers roughly offsets or slightly dominates its harmful effects from reduced social capital.

\section{Conclusions}

Other studies have highlighted the importance of local time-invariant characteristics on the relationship between economic variables and health. This study pushes a step further, finding that not accounting for time-invariant characteristics not only positively biases the estimated effect of inequality on mortality but also obscures an apparent negative effect of inequality on mortality. Our finding - that increases in inequality are associated with 
declines in mortality at the county level—suggests a change in course for the literature on health and inequality. In particular, we find that the emphasis in other research on potential psychosocial and resource allocation costs associated with higher inequality may miss important offsetting positives, and, in fact, these offsetting factors may dominate. 


\section{References}

Ben-Shlomo, Yoav, Ian R. White, and Michael Marmot. 1996. "Does the Variation in the Socioeconomic Characteristics of an Area Affect Mortality?" British Medical Journal 312(20):1013-14.

Clarkwest, Andrew and Christopher Jencks. 2003. Inequality and Mortality in Rich Countries: Who Owns the Null Hypothesis? Working paper. Cambridge, MA: John F. Kennedy School of Government, Harvard University.

Deaton, A. and D. Lubotsky. 2003. "Mortality, inequality and race in American cities and states." Social Science \& Medicine 56(6):1139-1153.

Deaton, Angus, and Christina Paxson. 2001. "Mortality, Education, Income and Inequality among American Cohorts." In Themes in the Economics of Aging, ed. David Wise. Chicago: University of Chicago Press.

Eibner, C. and W. Evans. 2005. "Relative Deprivation, Poor Health Habits and Mortality." Journal of Human Resources 40(3).

Gerdtham, U.G. and M. Johannesson. 2004. "Absolute income, relative income, income inequality, and mortality." Journal of Human Resources 39(1):228-247.

Judge, K., J.A. Mulligan, and M. Benzeval. 1998. "Income inequality and population health." Soc Sci Med 46(4-5):567-579.

Kaplan, George A., Elsie R. Pamuk, J. W. Lynch, Richard D. Cohen, and Jennifer L. Balfour. 1996. "Inequality in Income and Mortality in the United States: Analysis of Mortality and Potential Pathways." British Medical Journal 312(7037):999-1003.

Kawachi, Ichiro, and Bruce P. Kennedy. 1997. "The Relationship of Income Inequality to Mortality: Does the Choice of Indicator Matter?" Social Science and Medicine 45(7): 1121-27.

Kawachi, Ichiro, Bruce P. Kennedy, Kimberly Lochner, and Deborah Prothrow-Stith. 1997. "Social Capital, Income Inequality and Mortality." American Journal of Public Health 87(9):1491-98.

Kennedy, Bruce P., Ichiro Kawachi, and Deborah Prothrow-Stith. 1996a. "Income Distribution and Mortality: Cross-Sectional Ecological Study of the Robin-Hood Index in the United States." British Medical Journal 312(7037):1004-1007.

Kondo, N., G. Sembajwe, I. Kawachi, R.M. van Dam, S.V. Subramanian, Z. Yamagata. 2009. "Income Inequality, Mortality, and Self Rated Health: Meta-Analysis of Multilevel Studies.” British Medical Journal 339(b4471):1-9. 
Leigh, A. and C. Jencks. 2007. "Inequality and mortality: long-run evidence from a panel of countries." J Health Econ 26(1):1-24.

Lobmayer, P. and R. Wilkinson. 2000. "Income, inequality and mortality in 14 developed countries." Sociology of Health \& Illness 22(4):401-414.

Lochner, K., E. Pamuk, D. Makuc, B.P. Kennedy, and I. Kawachi. 2001. "State-level income inequality and individual mortality risk: a prospective, multilevel study." Am J Public Health 91(3):385-391.

Lynch, J.W., G.A. Kaplan, E.R. Pamuk, R.D. Cohen, K.E. Heck, J.L. Balfour, and I.H. Yen. 1998. "Income inequality and mortality in metropolitan areas of the United States." Am J Public Health 88(7):1074-1080.

Lynch, J.W., G.D. Smith, S. Harper, M. Hillemeier, N. Ross, G. Kaplan, and M. Wolfson. 2004. "Is Income Inequality a Determinant of Population Health? Part 1. A Systematic Review." Milbank Quarterly 82(1):5-99.

Lynch, J.W., G.D. Smith, M. Hillemeier, M. Shaw, T. Raghunathan, and G. Kaplan. 2001. "Income inequality, the psychosocial environment, and health: comparisons of wealthy nations." Lancet 358(9277):194-200.

Mellor, J. and J. Milyo. 2002. "Income Inequality and Health Status in the United States: Evidence from the Current Population Survey." The Journal of Human Resources 37(3):510-539.

—. 2003. "Is Exposure to Income Inequality a Public Health Concern? Lagged Effects of Income Inequality on Individual and Population Health." Health Services Research 38(1p1):137-151.

Ross, N.A., M.C. Wolfson, J.R. Dunn, J.M. Berthelot, G.A. Kaplan, and J.W. Lynch. 2000. "Relation between income inequality and mortality in Canada and in the United States: cross sectional assessment using census data and vital statistics." BMJ 320(7239):898-902.

Sanmartin, C., N.A. Ross, S. Tremblay, M. Wolfson, J.R. Dunn, and J. Lynch. 2003. "Labour market income inequality and mortality in North American metropolitan areas." J Epidemiol Community Health 57(10):792-797.

Shi, L., J. Macinko, B. Starfield, J. Wulu, J. Regan, and R. Politzer. 2003. "The relationship between primary care, income inequality, and mortality in US States, 1980-1995." $J$ Am Board Fam Pract 16(5):412-422.

Wilkinson, Richard G. 1992. "Income Distribution and Life Expectancy." British Medical Journal 304(6820): 165-6. 
Table 1. Poisson. All Cause Mortality \& 95/20 Percentile Ratio

\begin{tabular}{|c|c|c|c|c|c|c|c|c|}
\hline & \multicolumn{2}{|c|}{ (1) } & \multicolumn{2}{|c|}{$(2)$} & \multicolumn{2}{|c|}{ (3) } & \multicolumn{2}{|c|}{ (4) } \\
\hline & Coeff. & Z-stat & Coeff. & Z-stat & Coeff. & Z-stat & Coeff. & Z-stat \\
\hline \multicolumn{9}{|l|}{ Panel A. Inequality Measure } \\
\hline 95/20 Ratio (by county) & 0.023 & 5.909 & 0.014 & 3.033 & 0.003 & 0.380 & -0.038 & -2.493 \\
\hline \multicolumn{9}{|l|}{ Panel B. Selected Control Variables* } \\
\hline log(median income) (by county) & & & -0.469 & -13.678 & -0.047 & -0.574 & 0.323 & 2.525 \\
\hline poverty rate (by county*race) & & & -0.709 & -5.951 & -0.396 & -3.189 & -0.425 & -6.647 \\
\hline unemployment rate (by county) & & & & & -0.287 & -0.677 & -0.648 & -1.299 \\
\hline crime rate (by county) & & & & & 0.000 & -0.089 & 0.000 & 0.594 \\
\hline education: less than HS (\% county pop) & & & & & -0.186 & -0.366 & 9.646 & 9.091 \\
\hline education: HS but no diploma (\% county pop) & & & & & 1.343 & 2.243 & 9.116 & 8.604 \\
\hline education: HS grad/equiv. (\% county pop) & & & & & -0.568 & -1.238 & 4.355 & 4.327 \\
\hline education: some college, no degree (\% county pop) & & & & & -0.505 & -0.745 & 2.452 & 2.349 \\
\hline education: associate degree (\% county pop) & & & & & -1.625 & -1.975 & 5.953 & 4.330 \\
\hline education: bachelor degree (\% county pop) & & & & & -1.099 & -1.872 & 6.023 & 4.586 \\
\hline education: graduate/prof degree (\% county pop) & & & & & -0.680 & -0.903 & -1.617 & -1.236 \\
\hline race: black (\% county pop) & & & & & -0.111 & -1.282 & 0.578 & 1.557 \\
\hline race: other (\% county pop) & & & & & 0.145 & 1.149 & -0.453 & -0.407 \\
\hline age: 0-19 (\% county pop) & & & & & -1.444 & -3.344 & -4.798 & -6.836 \\
\hline age: 65+ (\% county pop) & & & & & -0.735 & -1.861 & 1.569 & 2.240 \\
\hline Number of Observations (Age*Race*Sex*Year*County Cells) & \multicolumn{2}{|c|}{326566} & \multicolumn{2}{|c|}{326299} & \multicolumn{2}{|c|}{311275} & \multicolumn{2}{|c|}{311275} \\
\hline State FE & \multicolumn{2}{|c|}{ NO } & \multicolumn{2}{|c|}{ NO } & \multicolumn{2}{|c|}{ NO } & \multicolumn{2}{|c|}{ NO } \\
\hline County FE & \multicolumn{2}{|c|}{ NO } & \multicolumn{2}{|c|}{ NO } & \multicolumn{2}{|c|}{ NO } & \multicolumn{2}{|c|}{ YES } \\
\hline
\end{tabular}

*Other included control variables (whose coefficients are not shown to save space) are: year X age interactions, year X race interactions, gender X year2000 interaction, gender, squared median income, family size, marriage categories (by male and female: never married, married, separated, divorced, widowed, other), population density, share of county population on social security disability, share of population living in institutions, latitude, and longitude. 
Table 2. Poisson. All Cause Mortality \& Gini Coefficient

\begin{tabular}{|c|c|c|c|c|c|c|c|c|}
\hline & \multicolumn{2}{|c|}{ (1) } & \multicolumn{2}{|c|}{ (2) } & \multicolumn{2}{|c|}{ (3) } & \multicolumn{2}{|c|}{ (4) } \\
\hline & Coeff. & Z-stat & Coeff. & Z-stat & Coeff. & Z-stat & Coeff. & Z-stat \\
\hline \multicolumn{9}{|l|}{ Panel A. Inequality Measure } \\
\hline gini (by county) & 1.049 & 5.279 & 0.620 & 2.525 & 0.058 & 0.148 & -0.262 & -0.752 \\
\hline \multicolumn{9}{|l|}{ Panel B. Selected Control Variables* } \\
\hline log(median income) (by county) & & & -0.472 & -13.562 & -0.050 & -0.595 & 0.460 & 3.773 \\
\hline poverty rate (by county*race) & & & -0.689 & -5.717 & -0.393 & -3.135 & -0.431 & -6.745 \\
\hline unemployment rate (by county) & & & & & -0.266 & -0.622 & -0.800 & -1.689 \\
\hline crime rate (by county) & & & & & 0.000 & -0.107 & 0.000 & 0.592 \\
\hline education: less than HS (\% county pop) & & & & & -0.179 & -0.366 & 9.901 & 8.969 \\
\hline education: HS but no diploma (\% county pop) & & & & & 1.356 & 2.273 & 9.248 & 8.496 \\
\hline education: HS grad/equiv. (\% county pop) & & & & & -0.574 & -1.255 & 4.589 & 4.405 \\
\hline education: some college, no degree (\% county pop) & & & & & -0.520 & -0.762 & 2.855 & 2.601 \\
\hline education: associate degree (\% county pop) & & & & & -1.611 & -1.923 & 6.559 & 4.584 \\
\hline education: bachelor degree (\% county pop) & & & & & -1.098 & -1.850 & 6.090 & 4.395 \\
\hline education: graduate/prof degree (\% county pop) & & & & & -0.620 & -0.843 & -2.528 & -1.947 \\
\hline race: black (\% county pop) & & & & & -0.108 & -1.252 & 0.722 & 1.616 \\
\hline race: other (\% county pop) & & & & & 0.141 & 1.151 & -0.842 & -0.736 \\
\hline age: 0-19 (\% county pop) & & & & & -1.431 & -3.281 & -4.890 & -6.518 \\
\hline age: 65+ (\% county pop) & & & & & -0.738 & -1.865 & 1.690 & 2.351 \\
\hline Number of Observations (Age*Race*Sex*Year*County Cells) & \multicolumn{2}{|c|}{326566} & \multicolumn{2}{|c|}{326343} & \multicolumn{2}{|c|}{311275} & \multicolumn{2}{|c|}{311275} \\
\hline State FE & \multicolumn{2}{|c|}{ NO } & \multicolumn{2}{|c|}{ NO } & \multicolumn{2}{|c|}{ NO } & \multicolumn{2}{|c|}{ NO } \\
\hline County FE & \multicolumn{2}{|c|}{ NO } & \multicolumn{2}{|c|}{ NO } & \multicolumn{2}{|c|}{ NO } & \multicolumn{2}{|c|}{ YES } \\
\hline
\end{tabular}

*Other included control variables (whose coefficients are not shown to save space) are: year $\mathrm{X}$ age interactions, year $\mathrm{X}$ race interactions, gender $\mathrm{X}$ year2000 interaction, gender, squared median income, family size, marriage categories (by male and female: never married, married, separated, divorced, widowed, other), population density, share of county population on social security disability, share of population living in institutions, latitude, and longitude. 
Table 3. Poisson. All Cause Mortality \& $95 / 50$ and 50/20 Interpercentile Ratios

\begin{tabular}{|c|c|c|c|c|c|c|c|c|}
\hline & \multicolumn{2}{|c|}{ (1) } & \multicolumn{2}{|c|}{$(2)$} & \multicolumn{2}{|c|}{ (3) } & \multicolumn{2}{|c|}{ (4) } \\
\hline & Coeff. & Z-stat & Coeff. & Z-stat & Coeff. & Z-stat & Coeff. & Z-stat \\
\hline \multicolumn{9}{|l|}{ Panel A. Inequality Measure } \\
\hline 95/50 Ratio (by county) & -0.063 & -3.225 & -0.026 & -1.310 & 0.005 & 0.162 & -0.105 & -2.519 \\
\hline 50/20 Ratio (by county) & 0.311 & 8.820 & 0.186 & 4.665 & 0.022 & 0.480 & -0.067 & -1.015 \\
\hline \multicolumn{9}{|l|}{ Panel B. Selected Control Variables* } \\
\hline log(median income) (by county) & & & -0.424 & -12.140 & -0.047 & -0.556 & 0.320 & 2.394 \\
\hline poverty rate (by county*race) & & & -0.752 & -6.221 & -0.400 & -3.202 & -0.428 & -6.725 \\
\hline unemployment rate (by county) & & & & & -0.293 & -0.684 & -0.727 & -1.561 \\
\hline crime rate (by county) & & & & & 0.000 & -0.100 & 0.000 & 0.497 \\
\hline education: less than HS (\% county pop) & & & & & -0.170 & -0.347 & 9.772 & 9.095 \\
\hline education: HS but no diploma (\% county pop) & & & & & 1.329 & 2.217 & 9.167 & 8.603 \\
\hline education: HS grad/equiv. (\% county pop) & & & & & -0.546 & -1.206 & 4.442 & 4.378 \\
\hline education: some college, no degree (\% county pop) & & & & & -0.486 & -0.719 & 2.523 & 2.401 \\
\hline education: associate degree (\% county pop) & & & & & -1.630 & -1.958 & 6.005 & 4.412 \\
\hline education: bachelor degree (\% county pop) & & & & & -1.066 & -1.743 & 6.208 & 4.557 \\
\hline education: graduate/prof degree (\% county pop) & & & & & -0.662 & -0.885 & -1.586 & -1.203 \\
\hline race: black (\% county pop) & & & & & -0.112 & -1.301 & 0.669 & 1.679 \\
\hline race: other (\% county pop) & & & & & 0.141 & 1.140 & -0.590 & -0.524 \\
\hline age: 0-19 (\% county pop) & & & & & -1.439 & -3.313 & -4.912 & -6.793 \\
\hline age: $65+(\%$ county pop $)$ & & & & & -0.716 & -1.748 & 1.624 & 2.294 \\
\hline Number of Observations (Age*Race*Sex*Year*County Cells) & \multicolumn{2}{|c|}{326566} & \multicolumn{2}{|c|}{326299} & \multicolumn{2}{|c|}{311275} & \multicolumn{2}{|c|}{311275} \\
\hline State FE & \multicolumn{2}{|c|}{ NO } & \multicolumn{2}{|c|}{ NO } & \multicolumn{2}{|c|}{ NO } & \multicolumn{2}{|c|}{ NO } \\
\hline County FE & \multicolumn{2}{|c|}{ NO } & \multicolumn{2}{|c|}{ NO } & \multicolumn{2}{|c|}{ NO } & \multicolumn{2}{|c|}{ YES } \\
\hline
\end{tabular}

*Other included control variables (whose coefficients are not shown to save space) are: year X age interactions, year X race interactions, gender $\mathrm{X}$ year2000 interaction, gender, squared median income, family size, marriage categories (by male and female: never married, married, separated, divorced, widowed, other), population density, share of county population on social security disability, share of population living in institutions, latitude, and longitude. 
Table 4. Poisson. Mortality By Cause \& Measures of Inequality

\begin{tabular}{|c|c|c|c|c|c|c|c|c|}
\hline & \multirow{2}{*}{\multicolumn{2}{|c|}{$\begin{array}{c}\text { (1) } \\
\text { Gini Coefficient }\end{array}$}} & \multirow{2}{*}{\multicolumn{2}{|c|}{$\begin{array}{c}\text { (2) } \\
\text { 95:20 Ratio }\end{array}$}} & \multicolumn{4}{|c|}{ (3) } \\
\hline & & & & & \multicolumn{2}{|c|}{ 95:50 Ratio } & \multicolumn{2}{|c|}{ 50:20 Ratio } \\
\hline & Coeff. & Z-stat & Coeff. & Z-stat & Coeff. & Z-stat & Coeff. & Z-stat \\
\hline Cancer & -0.704 & -1.810 & -0.033 & -2.339 & -0.089 & -2.264 & -0.084 & -1.294 \\
\hline Heart Attack & 0.003 & 0.007 & -0.002 & -0.091 & 0.062 & 1.009 & -0.072 & -0.709 \\
\hline Stroke & -0.582 & -1.140 & -0.045 & -2.306 & -0.043 & -0.738 & -0.172 & -2.017 \\
\hline Accident & -0.656 & -1.866 & -0.036 & -3.210 & -0.019 & -0.529 & -0.171 & -3.521 \\
\hline Lung Disease & -0.246 & -0.470 & -0.019 & -1.106 & -0.048 & -0.876 & -0.042 & -0.550 \\
\hline Diabetes & -0.870 & -1.356 & -0.028 & -1.145 & -0.083 & -1.324 & -0.020 & -0.155 \\
\hline Suicide & 0.264 & 0.487 & -0.022 & -1.443 & -0.022 & -0.419 & -0.093 & -1.525 \\
\hline Liver Failure & -2.434 & -3.195 & -0.076 & -2.704 & -0.176 & -2.468 & -0.192 & -1.359 \\
\hline Homicide & -2.600 & -1.918 & -0.187 & -4.833 & -0.602 & -4.141 & -0.482 & -3.535 \\
\hline
\end{tabular}

* Each row of column (1) shows the coefficients and z-statistics on the Gini for a Poisson regression of that cause's mortality frequency on the Gini, county fixed effects, and all of the same control variables included in the regressions in Tables 1-3 (column (4)). Columns (2) and (3) are analogous but use alternative inequality measures. 
Figure 1. Scatter Plot: 95/20 Percentile Ratio vs. All-Cause Mortality Rate

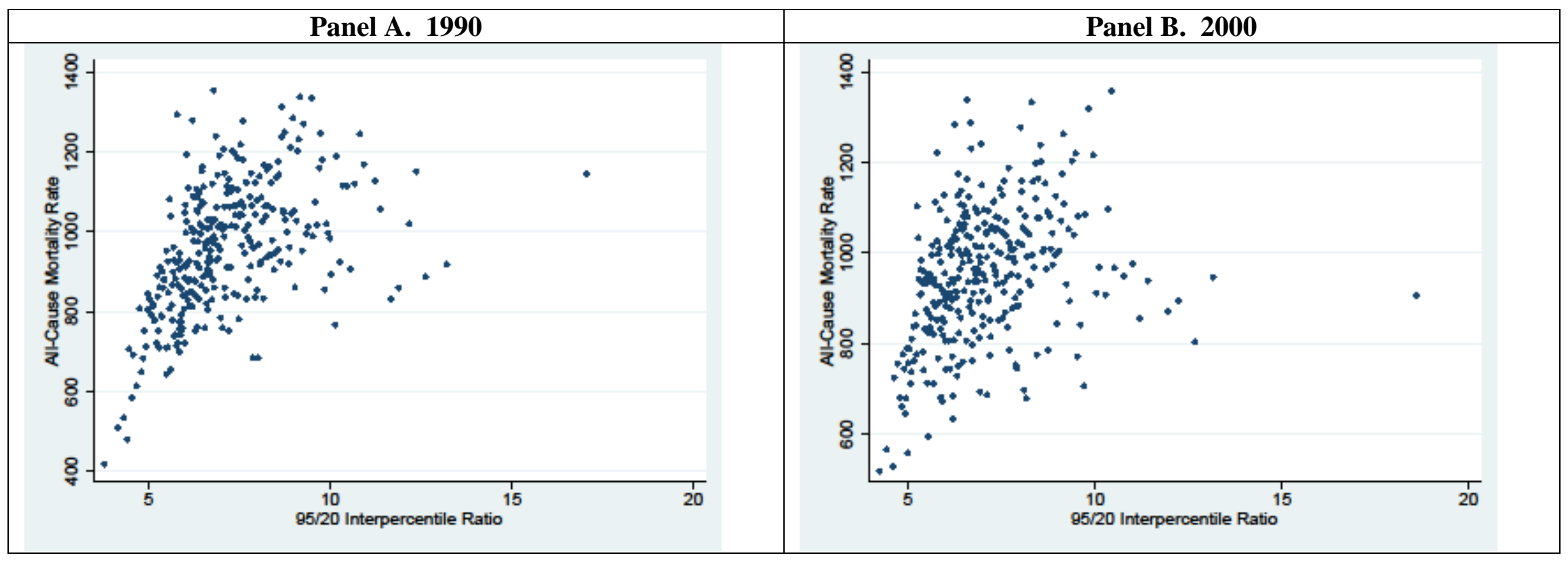

*Each dot represents a bin of approximately 10 counties. The $\mathrm{x}$ value for each bin is the mean 95/20 percentile ratio over the 10 counties; the $y$ value is the mean all-cause mortality rate. 
Figure 2. 95/20 Percentile Ratio

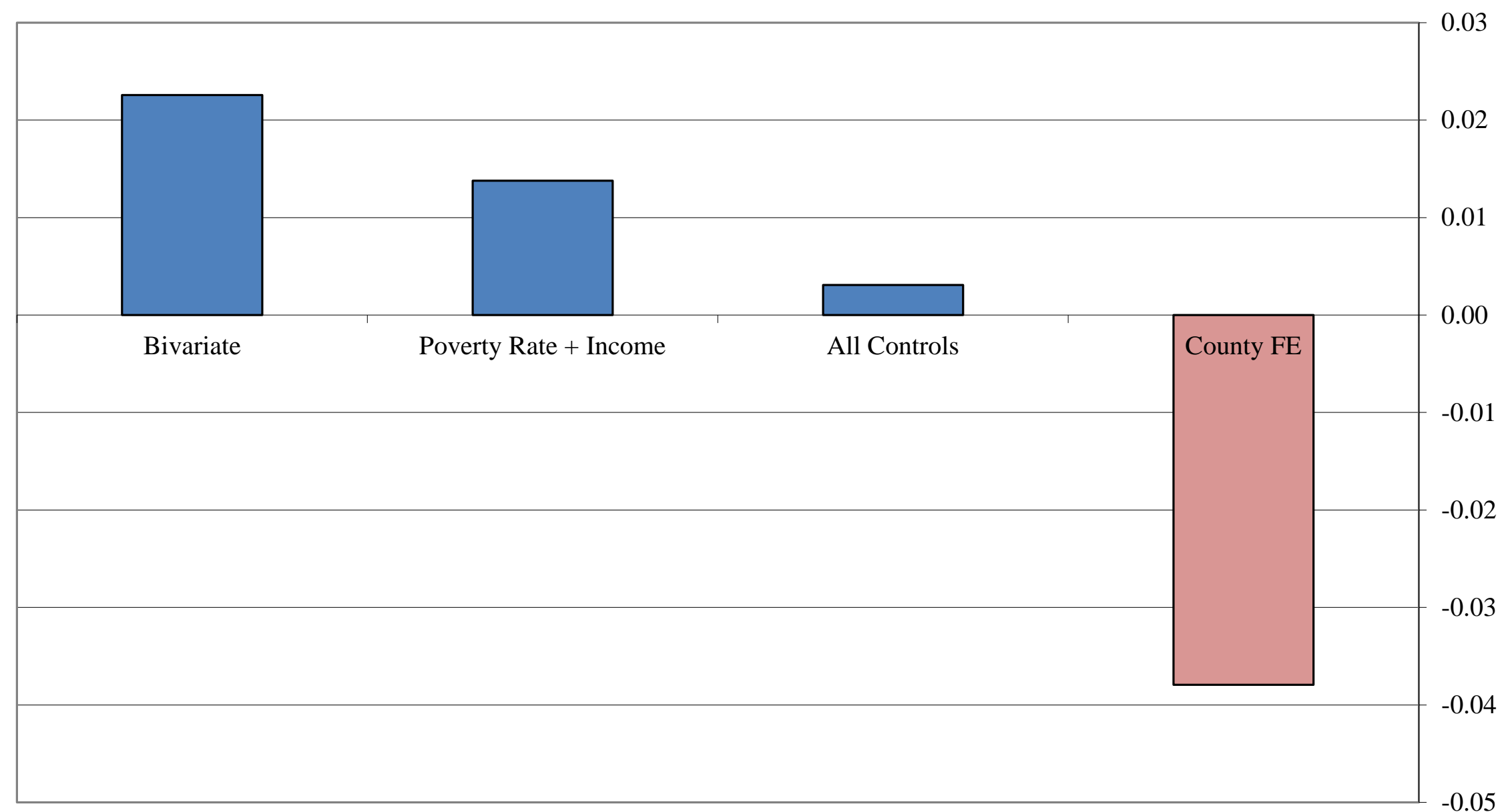

Bivariate $=$ Bivariate regression on inequality (as in Table 1-3, Column 1); Poverty Rate + Income $=$ additionally control for poverty rate and median income (Table 1-3, Column 2); All Controls = Include full set of observable control variables (Table 1-3, Column 3); County $\mathrm{FE}=$ Add county fixed effects (Table 1-3, Column 4). 